\title{
The Effect of Oral and Nasal Breathing on Pain Perception during Inferior Alveolar Nerve Block
}

\author{
USMAN SANA ${ }^{1}$, SHAKEEL AHMAD ${ }^{2}$, IFFAT UMAIR NIAZI ${ }^{3}$, NAVEED INAYAT ${ }^{4}$, MUHAMMAD MUDDASSAR $^{5}$, MIRZA \\ ABDUL RAUF 6 \\ ${ }^{1}$ Assistant Professor and Head Department of Operative Dentistry, Islam Dental College, Sialkot. \\ ${ }^{2}$ Associate Professor, Department of OMFS, Islam Dental College, Sialkot. \\ ${ }^{3}$ Registrar, Department of Operative Dentistry, Islam Dental College, Sialkot. \\ ${ }^{4}$ Associate Professor and Head Department of Prosthodontics. Islam Dental College, Sialkot. \\ ${ }^{5}$ Assistant Professor, Oral Medicine, Islam Dental College, Sialkot \\ ${ }^{6}$ Professor and Head Department of OMFS, Islam Dental College, Sialkot. \\ Correspondence to Dr. Naveed Inayat, Email: naveedinayat092@gmail.com, cell 03334436164
}

\begin{abstract}
Background: Dental pain and anxiety is challenging problem during procedures. Breathing pattern has strong correlation with pain perception. Nasal breather patients have less pain perception than oral breather.

Aim: To assess the role of breathing pattern and its impact on pain perception during painful dental procedures like dental local anaesthesia injections.

Methods: 300 patients were randomly selected from dental departments of Islam dental college during $1^{\text {st }}$ Jan 2020 till 31 Dec 2020 period. Verbal pain intensity scale was used among oral and nasal breather cases. Data was collected in proforma. Results were analysed statistically by SPSS version 23.

Results: Among 300 cases, 150 cases had mild pain, 89 cases had moderate pain and 61 cases had severe pain. Among 150 mild pain cases, 120 mild pain cases were nasal breather while89 oral breather cases had moderate pain and 61 oral breather cases had severe pain. Nasal breather patient had mild pain perception than oral breather.

Conclusions: Nasal breather has mild pain perception during dental anaesthesia than oral breather. Education and training of patient to practice nasal breathing can be recommended for oral breathers to become nasal breather preoperatively, this will help to reduce anxiety and pain perception during dental local anaesthesia injections.

Keyword: Oral and nasal breather, pain perception, local anaesthesia
\end{abstract}

\section{INTRODUCTION}

In dental procedures the simple action of administering local anesthetics often brings major anxiety and is associated with pain. Local anesthetic injection may not only generate pain and fear, but also be a triggering factor related to medical emergencies in dental offices, with vasodepressor syncope and hyperventilation as major psychogenic reactions $^{1,2}$.So, the association of anesthetic agents and techniques has been used to decrease nociceptive impulses in surgical stages $^{3}$ and different measures have been used to reduce dental pain of local anaesthesia in literature ${ }^{4}$ including nasal breathing training exercises ${ }^{4,5}$. Breathing is one of the most vital function of living bodies. Generally oral breather patients are irritable, stressed out and fatigued whereas nasal breathers have active parasympathetic system than oral breathesr ${ }^{5}$. Also, there is less amount of endogenous epinephrine released in nasal breathers which may contribute to lower anxiety and pain perception ${ }^{5,6}$. Studies have revealed that oral breather has more pain perception than nasal breather during $L A$ in dentistry ${ }^{5-9}$

In light of the above, this study was aimed at observing the difference in pain perception during IANB in oral and nasal breather.

Received on 13-01-2021

Accepted on 21-05-2021

\section{MATERIAL AND METHODS}

Three hundred cases were randomly selected from dental departments of Islam dental college during $1^{\text {st }}$ Jan 2020 till 31 December 2020 period. Selective age range was between 15 to 50 years age. Medically compromised and psychiatric patients were excluded. Approval of Islam dental ethically committee has explained to each patient about the study. Written consent was signed. Direct Inferior alveolar nerve block technique was used by same operator for anaesthetising mandible teeth. Verbal pain intensity scale was used. 0 with no pain, 1-3 mild pain, 4-7 moderate pain, 8-10 severe pain. Each patient was verbally explained about pain intensity scale. Benzocaine gel was not used before giving inferior alveolar nerve block with $2 \%$ lignocaine with 100,000 IU epinephrine. Immediately after dental LA, pain intensity scale of needle pricking was asked and documented in each patient's proforma.

\section{RESULTS}

Out of 300 patients, 128 cases were male and 172 cases were female. 167 cases were oral breather, among these, 68 cases were male and 99 cases were female. 133 cases were nasal breather, among these, 60 cases were male and 73 cases were female. There was no significant difference among nasal and oral breather cases with gender. 
Table 1: Correlation of gender with breathing pattern

\begin{tabular}{|l|l|l|l|}
\hline & Oral breather & Nasal breather & Total \\
\hline Male & 68 & 60 & 128 \\
\hline Female & 99 & 73 & 172 \\
\hline Total & 167 & 133 & 300 \\
\hline
\end{tabular}

Total mild pain cases were 150. 72 male cases had mild pain and 78 cases were female. Total moderate cases were 89 . 34 cases had moderate pain and 55 cases were female. Total severe cases were 61.21 cases were male and 39 cases were female. There were no significant differences among gender and pain severity.

Table 2: Correlation of gender with pain severity

\begin{tabular}{|l|c|c|c|}
\hline Pain scale & Male & Female & Total \\
\hline Mild & 72 & 78 & 150 \\
\hline Moderate & 34 & 55 & 89 \\
\hline Severe & 21 & 39 & 61 \\
\hline Total & 128 & 172 & 300 \\
\hline
\end{tabular}

Total 150 cases had mild pain. 120 cases were nasal breather, while 30 cases were oral breather. 89 cases had moderate pain. 6 cases were nasal breather and 83 cases were oral breather. 61 cases had severe pain. 7 cases were nasal breather and 54 cases were oral breather. Our study shows that nasal breather cases have mild pain perception. While moderate and severe pain perception is more common in oral breather. There was a statistically significant correlation between VAS and breathing $(p<0.05)$

Table 3: correlation of breathing pattern with pain severity

\begin{tabular}{|l|l|l|l|}
\hline Pain scale & Nasal breather & Oral breather & Total \\
\hline mild & 120 & 30 & 150 \\
\hline moderate & 6 & 83 & 89 \\
\hline severe & 7 & 54 & 61 \\
\hline Total & 133 & 167 & 300 \\
\hline
\end{tabular}

\section{DISCUSSION}

Local Anaesthesia is often the only perceived painful part of the medical or dental procedure, and fear associated with LA injection has been reported to be a factor in avoiding dental treatment ${ }^{1-4}$. Several factors may influence pain awareness, being this a complex process .Previous studies have examined variables that might be involved in painful LA injections and tested possible ways of minimizing the discomforts perceived at the time of injection. Variables included tissue distensibility ${ }^{10}$, speed of injection ${ }^{11}$, patient characteristics ${ }^{12}$, psychological aspects ${ }^{4}$ and temperature ${ }^{13}$. Simple and non-medical measures to reduce stress level during dental procedures are preferably adopted $^{6-8}$. Nasal breathing is a natural process than oral breathing. Inhaling and exhaling air through nose stimulates parasympathetic system that decreases heart rate and release less adrenaline ${ }^{9}$.Our body reacts differently to whether air comes into body through nose or mouth. Deep nasal breathing relaxes our body including increases of $\mathrm{CO}_{2}$ saturation in blood, which creates a calming effect. Cycle of hemisphere dominance controlled by closing nostrils and forcibly breathing through another nostril ${ }^{14-15}$. Studies have shown the most important and fundamental way of helping patients to relax physically is to teach them proper breathing techniques ${ }^{9,12-16}$.
Diaphragmatic breathing is a relaxed form of breathing. Use of the diaphragm for breathing reduces tension in the chest and provides more oxygen for the body per breath ${ }^{9}$. This is simple, safest cheapest, most accessible handle to control pain and fear during stressful procedures in dentistry $^{9}$.

In our study, nasal breathers reported mild pain (VAS 1-4) during inferior alveolar nerve block. On the contrary, oral breather cases reported moderate to severe pain (VAS 5-9).More mild pain cases were observed in nasal breather 120 as compared to oral breather 30 . Moderate pain cases were high 83 in oral breather as compared to nasal breathers 6 .Similarly, severe pain cases were high 54 in oral breathers as compared to nasal breathers ${ }^{7}$. Keeping in view the results of this study, we can devise measures to ensure patient nasal patency preoperatively. If there is nasal blockage, we can ask patient to use nasal decongestion spray preoperatively and also educate him regarding nasal breathing exercises to decrease the perception of pain during $\operatorname{IANB}^{9,14,15}$. Simple measures to enhance nasal breathing can also make positive effect on general body health and in decreasing dental local anaesthesia pain perception with no financial cost, as compared to doing procedure under IV sedation and General anaesthesia.

Limitation of the Study: The current study had a few limitations in terms of reliance on self-subjective evaluation of breathing patterns rather than a true picture ascertained through clinical assessment by a professional. Another limitation is of the method chosen for sampling as it was a public dental setting, the majority of study subjects were of low social strata and little educational background, and hence exclusion of people from other social strata may lead to under-representation of the general population.

\section{REFERENCES}

1. Reed KL, Malamed SF, Fonner AM. Local anesthesia part 2: technical considerations. Anesth Prog. 2012;59(3):127-36.

2. Kaufman E, Epstein JB, Naveh E, et al. A survey of pain, pressure, and discomfort induced by commonly used oral local anesthesia injections. Anesth Prog. 2005;52(5):122-7.

3. Schnaier TB, Vieira AM, Castilho DG, et al. Analgesia em procedimentos cirúrgicos de câncer de mama com bloqueio interpleural. Rev Dor. 2010;11(1):5-11.

4. Appukuttan DP. Strategies to manage patients with dental anxiety and dental phobia: literature review. Clin Cosmet Investig Dent. 2016;8:35-50. Published 2016 Mar 10. doi:10.2147/CCIDE.S63626

5. Russo MA, Santarelli DM, O'Rourke D. The physiological effects of slow breathing in the healthy human. Breathe (Sheff). 2017;13(4):298-309. doi:10.1183/20734735.009817

6. Suzuki M, Tanuma T (2020) The effect of nasal and oral breathing on airway collapsibility in patients with obstructive sleep apnea: Computational fluid dynamics analyses. PLoS ONE 15(4): e0231262

7. Sinha E, Rekha R, Nagashree SR. Anxiety of dental treatment among patients visiting primary health centers. $J$ Indian Assoc Public Health Dent 2019;17:235-40.

8. Fotedar S, Bhardwaj V, Fotedar V. Dental anxiety levels and factors associated with it among patients attending a dental teaching institute in Himachal Pradesh. SRM J Res Dent Sci 2016;7:153-7

9. Biggs QM, Kelly KS, Toney JD. The effects of deep diaphragmatic breathing and focused attention on dental 
anxiety in a private practice setting. $J$ Dent Hyg 2002;77(2):105-113.

10. Dworkin SF. Psychological considerations for facilitating anesthesia and sedation in dentistry. In: Dionne RA, Laskin $\mathrm{DM}$, editors. Anesthesia and Sedation in the Dental Office.New York, NY: Elsevier; 1986. pp. 15-28.

11. Locker D, Shapiro D, Liddell A. Negative dental experiences and their relationship to dental anxiety. Community Dent Health. 1996;63(1):86-92.

12. Milgrom P. Four dimensions of fear of dental injections. J Am Dent Assoc. 1997; 128:756-762.

13. Rood JP. The pressures created by inferior alveolar injections. Br Dent J.1978;144:280-282.
14. Fitzpatrick MF, McLean H, Urton AM, Tan A, O'Donnell D, Driver HS. Effect of nasal or oral breathing route on upper airway resistance during sleep. Eur Respir J. 2003 Nov;22(5):827-32.

15. Guilleminault C, Sullivan S. Towards Restoration of Continuous Nasal Breathing as the Ultimate Treatment. Goal in Pediatric Obstructive Sleep Apnoea. Enliven: Pediatrics and Neonatal Biology. Sept 1st 2014.

16. Jefferson $Y$. Mouth breathing: adverse effects on facial growth, health, academics and behaviour. General dentist. 2010 Jan- Feb; 58 (1): 18-25. 